Jurnal Epidemiologi Kesehatan Komunitas

7 (1), 2022, 357-374

\title{
JEKK
}

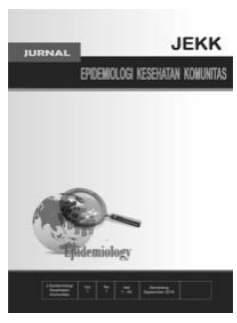

\section{Analisis Situasi Masalah Kesehatan Penyakit Menular di Provinsi Kalimantan Barat}

\author{
Luqman*, Mondastri Korib Sudaryo **, Antonius Suprayogi*** \\ *Field Epidemiology Training Program (FETP), Departemen Epidemiologi, Fakultas Kesehatan Masyarakat, \\ Universitas Indonesia, Depok, Jawa Barat, ****Dinas Kesehatan Provinsi Kalimantan Barat
}

\begin{abstract}
Background: Health problems in West Kalimantan are dominated by infectious diseases based on health data showing that the list of the top 10 diseases is dominated by infectious diseases, the CFR rate is still quite high and outbreaks routinely occur due to infectious diseases. The purpose of the situation analysis is to determine priorities for infectious disease problems in West Kalimantan in 2019. Methods: This research was conducted from December 2020 to February 2021 in West Kalimantan Province. The research method used is an assessment method whose results will be presented descriptively with quantitative and qualitative approaches. Determining the priority of the problem using the PAHO-Adapted Hanlon method with assessment criteria based on the size of the problem, seriousness of the problem, intervention effectiveness, inequity and institutional factors by means of interviews with related parties within the West Kalimantan Provincial Health Office.

Result: The results of the analysis of infectious disease problems in West Kalimantan Province show that the top 10 diseases are still dominated by infectious diseases such as diarrhea, TB and DHF. The CFR figure which is still quite high is contributed by TB, HIV/AIDS, diphtheria and DHF. In this study, TB was selected as a priority health problem because it obtained the highest PAHO score of 25.16. TB is still a major problem because case finding has not reached the national target of $80 \%$, there is still transmission in the community and cases of TB in children are still quite high.

Conclusion: Tuberculosis is a priority infectious disease problem in West Kalimantan. TB is the first priority problem in this study because case finding is not optimal, there is transmission in the community and there are still cases of TB in children. It is hoped that with monitoring and evaluation of training for cadres and health workers, screening of TB patients can be more massive and sensitive for providing complete TB treatment.
\end{abstract}

Keywords: Situation Analysis; Infectious Diseases; Tuberculosis; West Kalimantan. 


\section{Pendahuluan}

Pembangunan bidang kesehatan di Indonesia saat ini dihadapkan pada Triple Burden, yaitu penyakit menular yang jumlah kasus masih tinggi, penyakit tidak menular yang semakin meningkat prevalensinya serta penyakit yang dulunya sudah teratasi muncul kembali (re-emerging infectious diseases) atau munculnya penyakit-penyakit baru (newemerging infectious diseases). Pergeseran pola penyakit (transisi epidemiologi) dalam 30 tahun terakhir ini disebabkan karena perubahan gaya hidup (lifestyle) di masyarakat karena menyebabkan produktivitas masyarakat menjadi terganggu. ${ }^{1}$

Penyakit menular di Indonesia diklasifikasikan dalam tiga kelompok yaitu penyakit menular langsung, penyakit yang ditularkan melalui vektor dan zoonosis, serta penyakit yang dapat dikendalikan dengan imunisasi. ${ }^{2}$ Tiga penyakit menular yang perlu menjadi perhatian khusus adalah TB, HIV/AIDS dan malaria, selain penyakit yang dapat dicegah dengan imunisasi (PD3I). Perhatian khusus juga ditujukan untuk penyakit-penyakit infeksi baru yang menyebabkan kedaruratan kesehatan masyarakat, serta penyakit-penyakit tropis terabaikan (neglected tropical diseases). ${ }^{3}$

Bagi negara berkembang seperti Indonesia, permasalahan penyakit menular masih menjadi permasalahan rutin setiap tahunnya karena seringkali menimbulkan Kejadian Luar Biasa (KLB) sehingga menjadi beban bagi pemerintah dan kesengsaraan bagi masyarakat. Permasalahan utama yang masih di hadapi Indonesia pada lingkup penyakit menular yaitu kasus TB Indonesia merupakan salah satu dari lima negara dengan jumlah kasus TBC terbesar di dunia, kasus HIV mengalami peningkatan kasus infeksi HIV baru dengan estimasi 630.000 orang dengan HIV/AIDS (ODHA), cakupan Imunisasi Dasar
Lengkap (IDL) tahun 2018 baru sebesar 57,9\% dan sekitar $70 \%$ dari penyakit infeksi pada manusia yang (baru) muncul adalah penyakit zoonosis, seperti DBD dan Covid-19. ${ }^{3}$

Kalimantan Barat merupakan provinsi yang masih dibebani dengan permasalahan penyakit menular. Hasil analisis profil kesehatan menunjukkan bahwa CFR TB mengalami peningkatan dari $1,3 \%$ di tahun 2015 menjadi 3,3\% ditahun 2019, HIV masih belum menunjukkan trend penurunan kasus (dari 531 kasus ditahun 2015 meningkat menjadi 783 kasus di tahun 2019), Diare selalu masuk dalam nominasi tiga penyakit terbanyak ditahun 2017-2019, IR DBD masih berada diatas target (49 per 100.000 penduduk) dan CFR Difteri telah mencapai angka 7,14\% di tahun 2019. ${ }^{4}$ Hal tersebut merupakan sedikit gambaran permasalahan kesehatan dalam lingkup penyakit menular yang dihadapi di Kalimantan Barat.

Penyakit menular masih menjadi masalah kesehatan yang harus dihadapi di Provinsi Kalimantan Barat. Dalam hal mengatasi permasalahan tersebut dibutuhkan solusi penyelesaian serta perhatian serius dari pemangku kepentingan. Gambaran permasalahan awal kesehatan diatas membutuhkan analisa lebih lanjut sehingga perlu dilakukan identifikasi masalah dan penentuan prioritas masalah.

\section{Metode}

Penelitian ini menggunakan metode assessment yang hasilnya akan disajikan secara deskriptif dengan pendekatan kuantitatif dan kualitatif. Ruang lingkup penelitian ini adalah seluruh penyakit penyakit menular yang tercatat di Dinas Kesehatan Provinsi Kalimantan Barat pada periode 2015-2019. Penentuan prioritas masalah dilakukan dengan menggunakan metode PAHO adopted Hanlon melalui suatu pembobotan yang melibatkan partisipasi pemegang kebijakan internal 
instansi sehingga akan lebih objektif. Pejabat struktural Dinas Kesehatan Provinsi Kalimantan Barat yang dilibatkan yaitu Kepala Bidang Pengendalian Penyakit Menular, Kepala Seksi Surveilans dan Imunisasi, Kepala Seksi Pengendalian Penyakit Menular, Kepala Bidang Kesehatan Masyarakat dan beberapa orang pengelola Program Penyakit Menular di Dinas Kesehatan Provinsi Kalimantan Barat. Masing-masing memberikan penilaian terhadap masalah yang telah diidentifikasi berdasarkan formulir penilaian yang telah disediakan. Adapun indikator yang menjadi penilaian dalam metode PAHO adopted Hanlon yaitu:

- Komponen A: besarnya masalah, dengan range skor penilaian 0-10.

- Komponen B: keseriusan masalah, dengan range skor penilaian $0-20$.

- Komponen C: ffektivitas intervensi dengan range skor penilaian $0-10$.

- Komponen E: ketidakadilan, dengan range skor penilaian $0-5$.

- Komponen F: Faktor institusi dengan range skor penilaian $0.67-1.5$.

Hasil penilaian dari seluruh pasrtisipan akan di hitung rata-ratanya untuk selanjutnya dihitung nilai BPR (Basic Priority Rating) untuk menentukan prioritas masalah Kesehatan berdasarkan nilai tertinggi hasil pembobotan.

Basic Priority Rating $(B P R)=\frac{(A+B+E) C}{5.25} \times F$

\section{Hasil}

Berdasarkan hasil pengumpulan dan analisis data penyakit menular di Kalimantan Barat. maka teridentifikasi beberapa masalah penyakit menular dengan mempertimbangkan tren peningkatan kejadian kasus dalam beberapa tahun, angka kematian dan penyakit berpotensi KLB serta capaian target nasional maupun target daerah adalah sebagai berikut:

\section{Tuberkulosis (TB)}

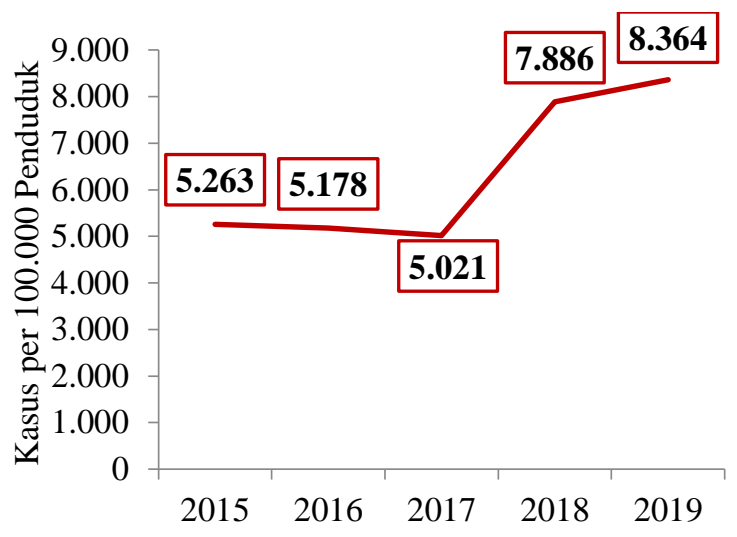

Sumber: Laporan Pencegahan dan Pengendalian Penyakit Menular Dinas Kesehatan Provinsi Kalimantan Barat Tahun 2015-2019

Gambar 1. Jumlah Kasus TB di Kalimantan Barat Tahun 2015-2019

Trend kasus TB pada periode 2015-2019 mengalami peningkatan jumlah kasus yaitu dari 5.262 kasus di tahun 2015 menjadi 8.364 kasus di tahun 2019.

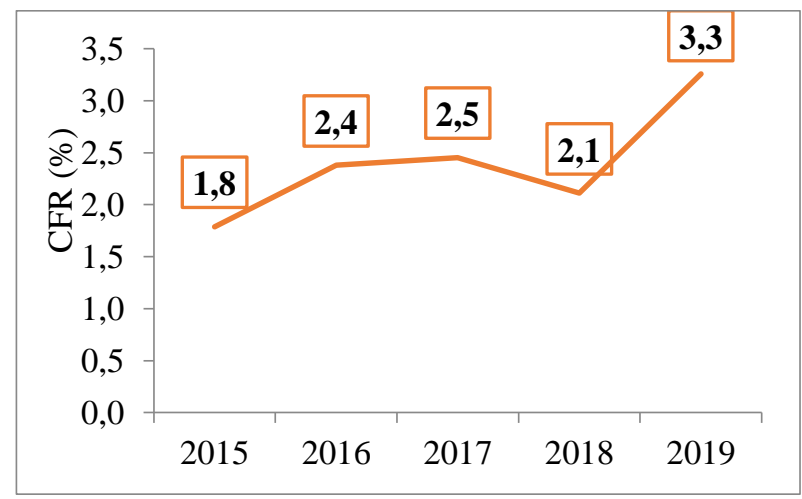

Laporan Pencegahan dan Pengendalian Penyakit Menular Dinas Kesehatan Provinsi Kalimantan Barat Tahun 2015-2019

Gambar 2. CFR TB di Kalimantan Barat Tahun 2015-2019

Trend CFR TB tahun 2015-2019 menunjukkan adanya peningkatan kasus yaitu dari $1,8 \%$ di tahun 2015 menjadi 3,3\% di tahun 2019. 


\section{HIV/AIDS}

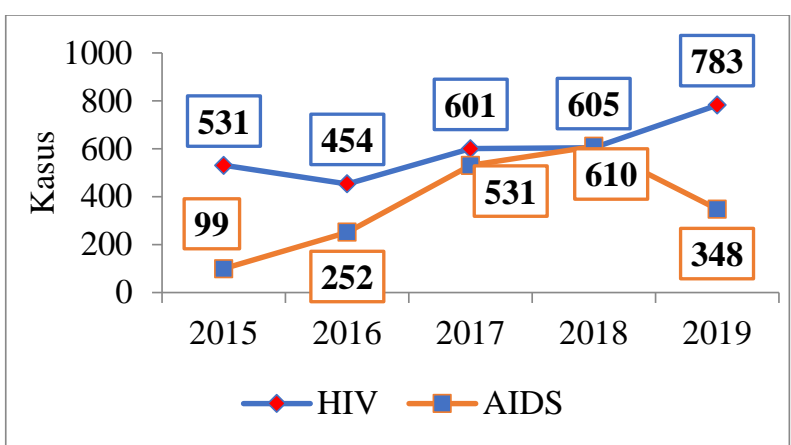

Sumber: Laporan Seksi Pemberantasan Penyakit Dinas Kesehatan Provinsi Kalimantan Barat Tahun 2015-2019

Gambar 3. Jumlah Kasus HIV/AIDS di Kalimantan Barat Tahun 2015-2019

Trend kasus HIV menunjukkan adanya peningkatan jumlah kasus yaitu dari 531 kasus di tahun 2015 menjadi 783 kasus di tahun 2019. Hal serupa terjadi pada kasus AIDS yaitu dari 99 kasus di tahun 2015 menjadi 610 pada tahun 2018, tetapi mengalami penurunan di tahun 2019 yaitu 348 kasus.

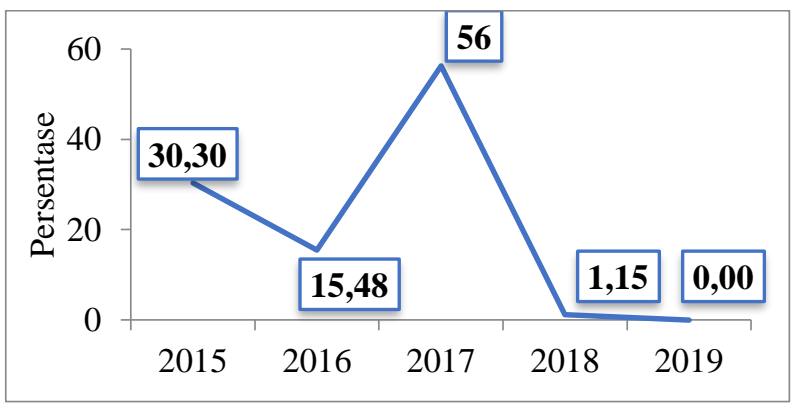

Sumber: Laporan Seksi Pemberantasan Penyakit Dinas Kesehatan Provinsi Kalimantan Barat Tahun 2015-2019

Gambar 4. CFR AIDS di Kalimantan Barat Tahun 2015-2019

CFR tertinggi AIDS terjadi di tahun 2017 yaitu mencapai $56 \%$ di tahun 2017. Kemudian menurun drastis menjadi 0\% di tahun 2019.

\section{Diare}

\begin{tabular}{cccc}
\hline Urutan & Tahun & Penyakit & Jumlah Kasus \\
\hline 1. & \multirow{2}{*}{2017} & Hipertensi & 89.627 \\
2. & Influenza & 83.543 \\
3. & & Diare & 58.717 \\
\hline 1. & \multirow{2}{*}{2018} & Influenza & 58.642 \\
2. & Hipertensi & 44.134 \\
3. & & Diare & 2.565 \\
\hline 1. & \multirow{2}{*}{2019} & Influenza & 23.326 \\
2. & & Diare & 16.593
\end{tabular}

\begin{tabular}{cccc}
\hline Urutan & Tahun & Penyakit & Jumlah Kasus \\
\hline 3. & & Hipertensi & 15.681 \\
\hline
\end{tabular}

Sumber: Seksi Surveilans dan Imunisasi Dinas Kesehatan Provinsi Kalimantan Barat Tahun 2017-2019

Tabel 1. Daftar Tiga Besar Penyakit di Kalimantan Barat Tahun 2017-2019

Diare selalu masuk ke dalam daftar 10 daftar penyakit terbanyak dan pada tahun 20172019 selalu masuk dalam peringkat tiga teratas.

\section{Kusta}

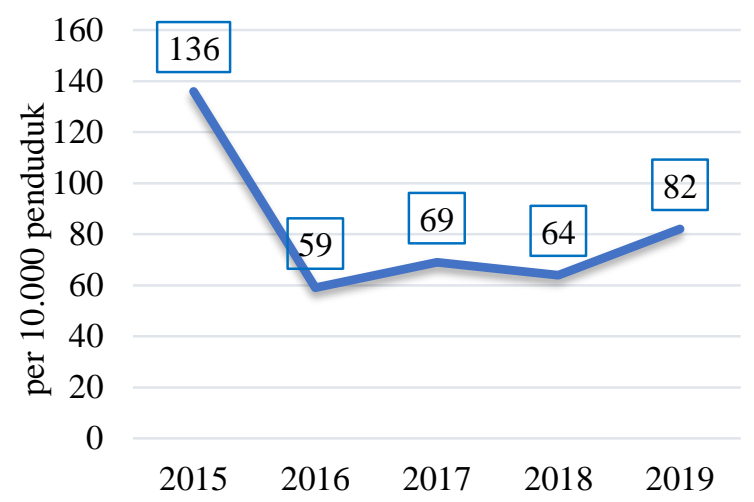

Sumber: Seksi Pencegahan dan Pengendalian Penyakit Menular Dinas Kesehatan Provinsi Kalimantan Barat Tahun 2015-2019

Gambar 5. Jumlah Kasus Baru Kusta di Kalimantan Barat Tahun 2015-2019

Terjadi trend peningkatan kasus baru Kusta pada periode 2016-2019 yaitu dari 59 kasus menjadi 82 kasus. Walaupun jumlahnya tidak sebanyak pada tahun 2015 yaitu 136 kasus.

\section{DBD}

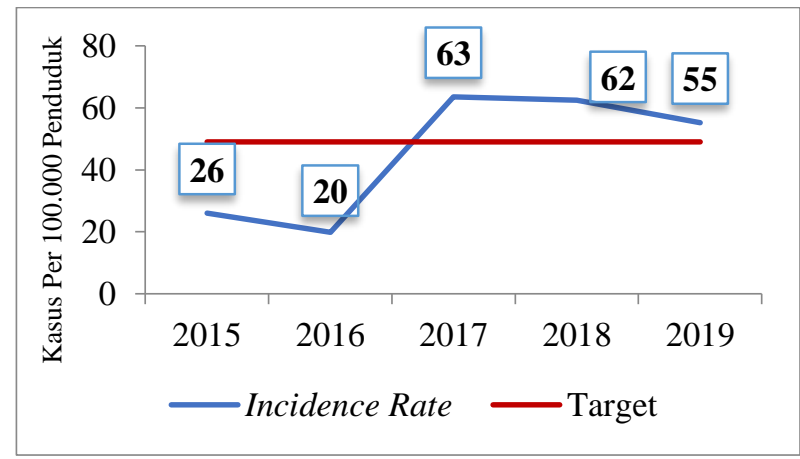

Sumber: Seksi Pencegahan dan Pengendalian Penyakit Menular Dinas Kesehatan Provinsi Kalimantan Barat Tahun 2015-2019

Gambar 6. IR DBD di Kalimantan Barat Tahun 2015-2019 
IR DBD pada tahun 2017-2019 berada diatas target yang ditetapkan Kemenkes RI yaitu sebesar 49 per 100.000 penduduk.

\section{Malaria}

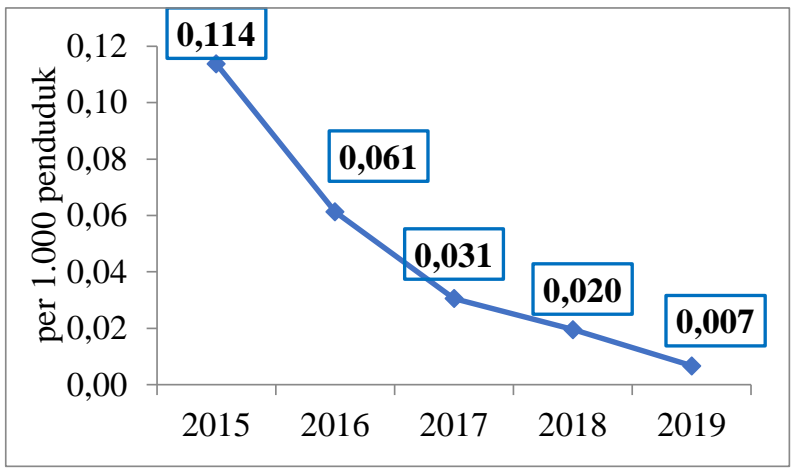

Sumber: Seksi Pencegahan dan Pengendalian Penyakit Menular Dinas Kesehatan Provinsi Kalimantan Barat

Gambar 7. Annual Parasite Incidence (API) Malaria di Kalimantan Barat Tahun 2015-2019

API Malaria per 1.000 penduduk pada tahun 2015-2019 telah menunjukkan trend penurunan kasus. Tetapi pada tahun 2020, dari $14 \mathrm{Kab} / \mathrm{Kota}$, hanya $5 \mathrm{Kab} / \mathrm{Kota}$ yang berhasil mencapai eliminasi malaria. ${ }^{4}$

\section{Filariasis}

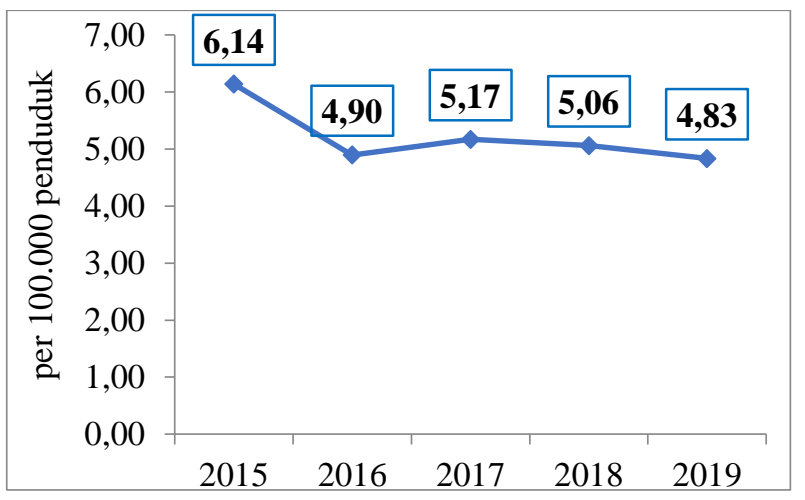

Sumber: Seksi Pencegahan dan Pengendalian Penyakit Menular Dinas Kesehatan Provinsi Kalimantan Barat Tahun 2015-2019

Gambar 8. Jumlah Angka Kesakitan Kasus Filariasis di Kalimantan Barat Tahun 20152019

Angka kesakitan per 100.000 penduduk akibat filariasis tahun 2015-2019 memiliki trend grafik menurun walaupun tidak signifikan. Sedangkan pada tahun 2019 tercatat ada sebanyak 5 kasus kematian dan sebanyak 11 dari $14 \mathrm{Kab} /$ Kota di Kalimantan Barat merupakan daerah endemis filariasis. ${ }^{4}$

\section{Difteri}

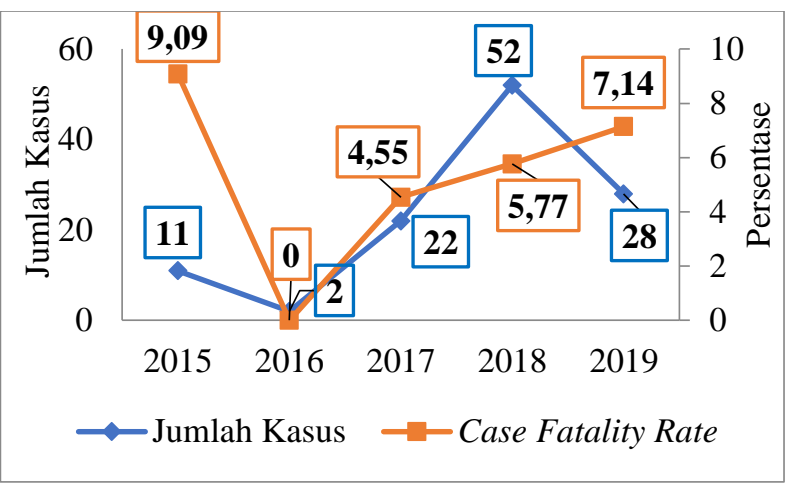

Sumber: Seksi Surveilans dan Imunisasi Dinas Kesehatan Provinsi Kalimantan Barat Tahun 2015-2019

Gambar 9. Jumlah Kasus dan CFR Difteri di Kalimantan Barat Tahun 2015-2019

Jumlah kasus Difteri mengalami peningkatan pada tahun 2016-2018 dan pada tahun 2019 tercatat ada sebanyak 28 kasus. CFR Difteri mengalami peningkatan yang cukup siginifikan pada tahun 2016-2019. Dari yang awalnya $0 \%$ di tahun 2016, meningkat menjadi 7,14\% di tahun 2019.

\section{Pertusis}

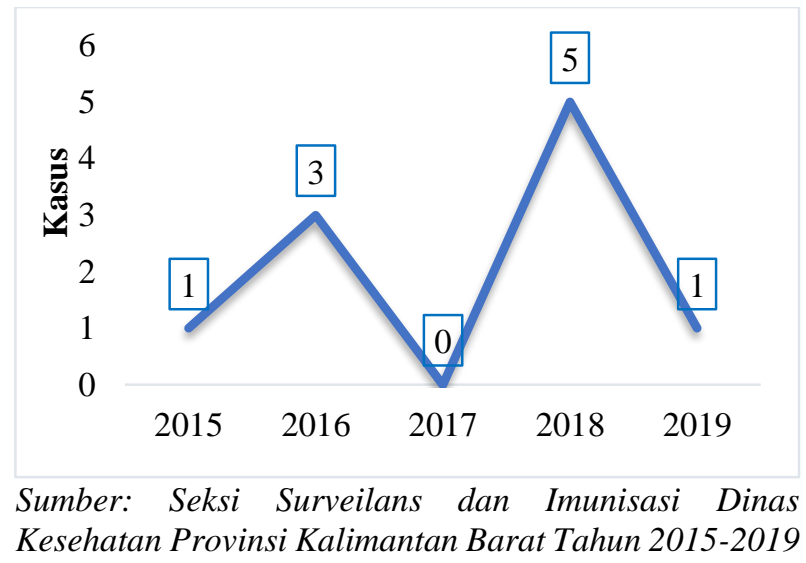

Gambar 10. Jumlah Kasus Pertusis di Kalimantan Barat Tahun 2015-2019

Selama tahun 2015-2019, teracatat kasus Pertusis paling tinggi terjadi ditahun 2018 yaitu sebanyak 5 kasus dan di tetapkan sebagai KLB. 


\section{Tetanus Neonatorum}

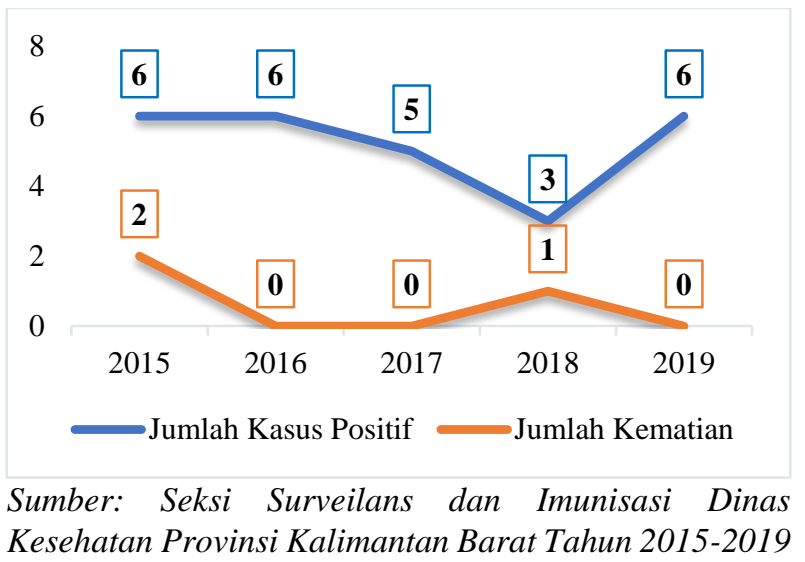

Gambar 11. Jumlah Kasus dan Kematian Tetanus Neonaotorum di Kalimantan Barat Tahun 2015-2019

Kasus positif Tetanus Neonatorum pada tahun 2015-2018 telah mengalami penurunan. Tetapi pada tahun 2019 kasusnya meningkat. Sedangkan CFR Tetanus Neonatorum masih termasuk tinggi karena mencapai 33,3\% yang terjadi pada tahun 2015 dan 2018.

\section{Hepatitis B}

\begin{tabular}{cc}
\hline Tahun & Jumlah Kasus \\
\hline 2015 & 31 \\
2016 & Tidak Ada Data \\
2017 & Tidak Ada Data \\
2018 & Tidak Ada Data \\
2019 & 0 \\
\hline
\end{tabular}

Sumber: Seksi Surveilans dan Imunisasi Dinas Kesehatan Provinsi Kalimantan Barat Tahun 2015-2019

Tabel 2. Kasus Hepatitis B di Kalimantan Barat Tahun 2015-2019

Selama periode tahun 2015-2019, Hepatitis B hanya terjadi di tahun 2015 yaitu sebanyak 31 kasus.

\section{AFP (Non Polio)}

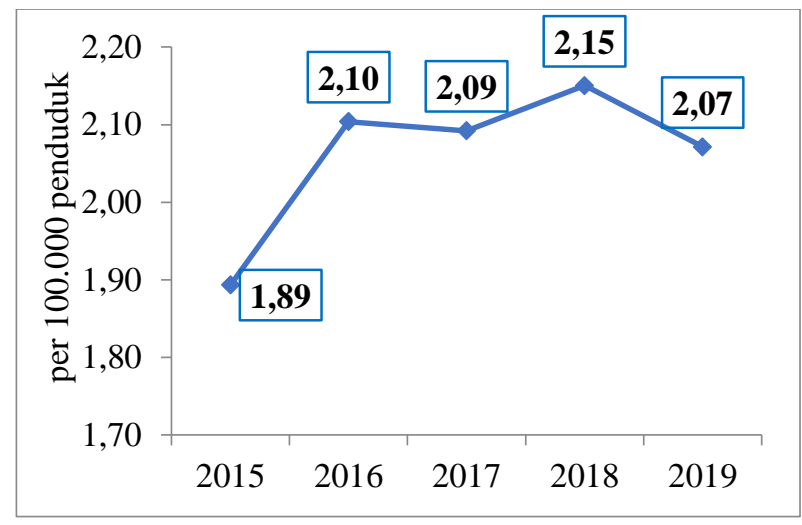

Sumber: Seksi Surveilans dan Imunisasi Dinas Kesehatan Provinsi Kalimantan Barat Tahun 2015-2019

Gambar 12. Kasus AFP (Non-Polio) Rate per 100.000 Penduduk di Kalimantan Barat Tahun 2015-2019

AFP (Non-Polio) Rate pada tahun 20162019 telah mencapai standar minimal penemuan kasus yang telah di tetapkan oleh Kemenkes RI yaitu minimal 2 per 100.000 populasi penduduk usia $<15$ tahun.

\section{Campak}

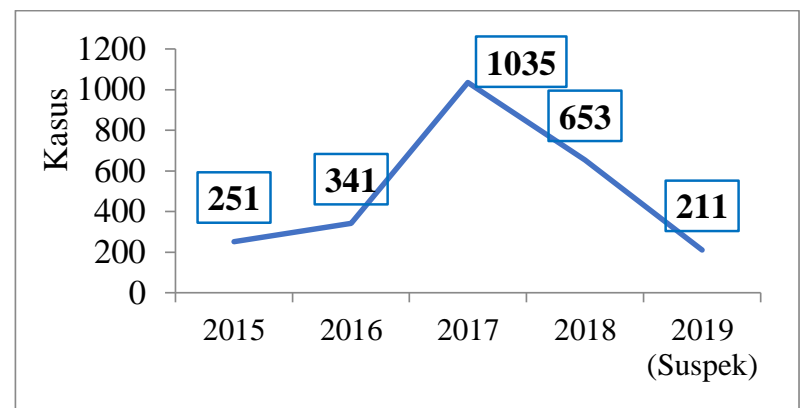

Sumber: Seksi Surveilans dan Imunisasi Dinas Kesehatan Provinsi Kalimantan Barat Tahun 2015-2019

Gambar 13. Jumlah Kasus Campak di Kalimantan Barat Tahun 2015-2019

Kasus Campak di tahun 2017 pernah mencapai 1.035 kasus, kemudian mengalami penurunun jumlah kasus pada periode 20152019. 


\section{Prioritas Masalah}

Berdasarkan hasil indepth interview kepada pihak-pihak terkait di lingkungan Dinas Kesehatan Provinsi Kalimantan Barat, diperoleh hasil bahwa Tuberkulosis (TB) menjadi prioritas utama masalah penyakit menular di Kalimantan Barat. Hasil skoring Tuberkulosis (TB) dengan metode PAHO adapted Hanlon adalah sebagai berikut:

Tabel 3. Rekapitulasi dan Skoring PAHO Masalah Penyakit Menular di Kalimantan Barat

\begin{tabular}{|c|c|c|c|c|c|c|c|}
\hline \multirow{2}{*}{$\begin{array}{c}\text { Daftar Penyakit } \\
\text { Menular }\end{array}$} & $\begin{array}{c}\text { A } \\
(0-10)\end{array}$ & $\begin{array}{c}\text { B } \\
(\mathbf{0 - 2 0})\end{array}$ & $\begin{array}{c}C \\
(0-10)\end{array}$ & $\begin{array}{c}\mathbf{E} \\
(\mathbf{0 - 5})\end{array}$ & $\begin{array}{c}F \\
(0.67-1.5)\end{array}$ & \multirow{2}{*}{$\begin{array}{c}\text { Basic } \\
\text { Priority } \\
\text { Rating } \\
\text { (BPR) } \\
\end{array}$} & \multirow{2}{*}{$\begin{array}{l}\text { Prioritas } \\
\text { Masalah }\end{array}$} \\
\hline & $\begin{array}{c}\text { Besarnya } \\
\text { Masalah }\end{array}$ & $\begin{array}{c}\text { Keseriusan } \\
\text { Masalah }\end{array}$ & $\begin{array}{l}\text { Efektifitas } \\
\text { Intervensi }\end{array}$ & $\begin{array}{l}\begin{array}{l}\text { Ketidak- } \\
\text { adilan }\end{array} \\
\end{array}$ & $\begin{array}{c}\text { Faktor } \\
\text { Instirusi }\end{array}$ & & \\
\hline $\begin{array}{l}\text { Tuberkulosis } \\
\text { (TB) }\end{array}$ & 6,00 & 13,64 & 6,18 & 2,73 & 0,96 & 25,16 & 1 \\
\hline $\mathrm{DBD}$ & 6,55 & 13,91 & 5,36 & 2,36 & 1,03 & 24,08 & 2 \\
\hline HIV/AIDS & 5,55 & 12,91 & 5,91 & 3,00 & 0,99 & 23,80 & 3 \\
\hline Difteri & 5,36 & 12,55 & 5,36 & 2,00 & 0,91 & 18,58 & 4 \\
\hline Malaria & 5,00 & 10,55 & 4,45 & 1,91 & 0,97 & 14,37 & 5 \\
\hline Hepatitis B & 4,82 & 9,45 & 4,55 & 1,91 & 1,00 & 14,06 & 6 \\
\hline Filariasis & 4,82 & 9,91 & 4,18 & 2,09 & 1,01 & 13,48 & 7 \\
\hline Kusta & 3,73 & 8,73 & 4,73 & 2,82 & 0,95 & 13,08 & 8 \\
\hline $\begin{array}{l}\text { Diare } \\
\text { Tetanus }\end{array}$ & 3,82 & 8,91 & 5,09 & 1,64 & 0,93 & 12,92 & 9 \\
\hline Neonatorum & 4,00 & 9,36 & 4,27 & 1,82 & 1,02 & 12,63 & 10 \\
\hline Campak & 3,73 & 7,82 & 4,82 & 1,82 & 0,89 & 10,90 & 11 \\
\hline Pertusis & 3,45 & 7,91 & 4,36 & 1,91 & 0,85 & 9,35 & 12 \\
\hline Polio & 3,09 & 7,36 & 4,36 & 1,73 & 0,89 & 9,00 & 13 \\
\hline
\end{tabular}

Sumber: Data Primer, 2020

Dalam penelitian ini TB terpilih menjadi prioritas masalah kesehatan karena memperoleh skor penilaian PAHO tertinggi yaitu sebesar 25,16. Beberapa alasan yang menjadikan TB sebagai masalah utama penyakit menular adalah trend kasus TB mengalami peningkatan jumlah kasus dimana pada tahun 2015 jumlah kasus TB sebanyak 5.262 kasus dan meningkat di tahun 2019 menjadi 8.364 kasus. Hal yang sama juga terjadi pada trend CFR TB di Kalimantan Barat. CFR TB di tahun 2015 sebesar 1,8\% untuk selanjutnya meningkat menjadi $3,3 \%$ ditahun 2019. ${ }^{4-8}$ 


\section{Pembahasan}

Analisis Penyebab Prioritas Masalah/Akar Masalah

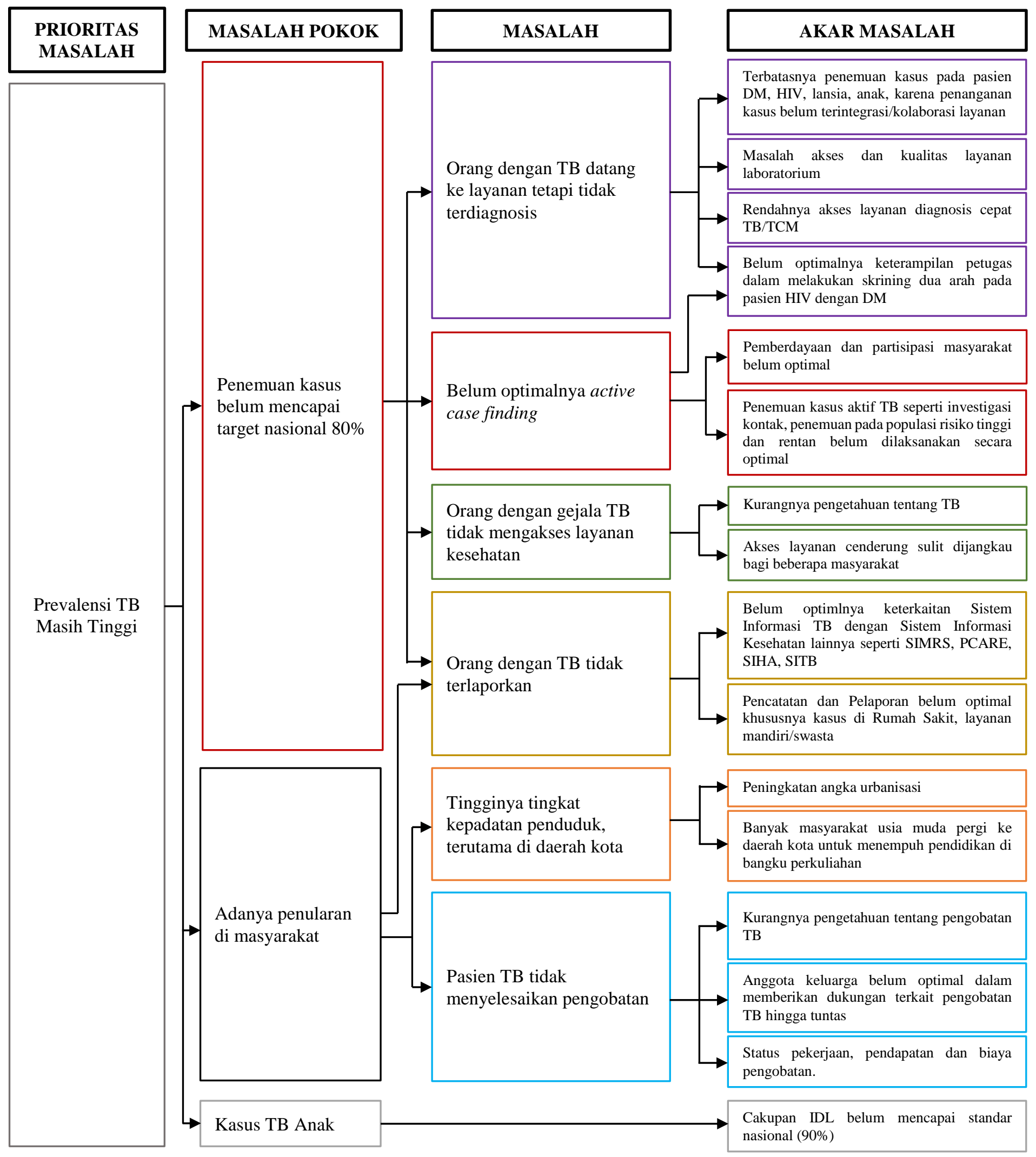

\section{Gambar 14. Analisis Penyebab Masalah TB di Kalimantan Barat}


Penentuan penyebab masalah menggunakan metode problem tree dengan menganalisis hasil observasi dokumen dan diskusi dengan pemegang program sehingga didapat berbagai faktor yang menyebabkan masalah di Kalimantan Barat. Hasil analisis situasi penyakit menular di Kalimantan Barat diperoleh hasil yang menjadi prioritas utama masalah kesehatan adalah TB. Gambar 14 menunjukkan bagan analisa akar masalah tingginya prevalensi $\mathrm{TB}$ di Kalimantan Barat. Berdasarkan hasil wawancara dan diskusi dengan pemangku kebijakan di Dinas Kesehatan Provinsi Kalimantan Barat diperoleh data beberapa hal yang berhubungan dengan masih tingginya prevalensi TB.

1. Penemuan kasus belum mencapai target nasional $80 \%$

\subsection{Orang dengan TB datang ke layanan tetapi tidak terdiagnosis}

Hasil wawancara kapada pemegang program TB di Dinas Kesehatan Kalimantan Barat diketahui bahwa salah satu faktor rendahnya $\mathrm{CDR}$ TB adalah penderita $\mathrm{TB}$ yang belum terdiagnosis. Hal ini karena masih terbatasnya screening TB pada pasien DM, HIV, lansia dan anak serta penanganan kasus yang belum saling terintegrasi di setiap poli di Puskesmas. Khususnya pada pasien DM dan HIV yang merupakan kelompok rentan terpapar TB. Berdasarkan Laporan Global TB tahun 2018, estimasi insiden kasus TB di Indonesia sebanyak 842.000 kasus (termasuk 36.000 kasus TB-HIV) dan 23.000 kasus TBRR/MDR. Dari total kasus tersebut, hanya 446.732 kasus TB (53\%) yang dilaporkan sehingga masih terdapat 395.268 kasus TB yang belum ditemukan dan dilaporkan (missing cases). ${ }^{9}$ Berdasarkan Studi Patient Pathway Analysis TB, data pola masyarakat dengan gejala TB dalam hal mencari pengobatan awal lebih memilih fasilitas pelayanan kesehatan (fasyankes) swasta (74\%) dibanding puskesmas dan RS pemerintah (24\%). Hal ini mungkin dikarenakan masyarakat lebih mudah menuju akses swasta (private) dibandingkan publik. Rasio pencarian pengobatan di fasyankes swasta paling besar ada di farmasi/apotek (52\%), DPM (19\%) dan RS $(3 \%) .{ }^{10}$ Dari kondisi di atas yang menunjukkan tingginya prevalensi TB di Indonesia dan angka penemuan kasus yang rendah, diperlukan adanya penguatan jejaring layanan dengan melibatkan fasyankes pemerintah maupun swasta. ${ }^{11}$

Faktor lainnya adalah belum optimalnya keterampilan petugas dalam melakukan skrining dua arah pada pasien HIV dengan DM sehingga kasus TB pada pasien tersebut tidak terdeteksi. Masa kerja berkaitan erat dengan pengalaman dalam bekerja. Pengalaman kerja yang monoton dan cenderung menimbulkan kejenuhan bisa jadi dapat mempengaruhi kinerja seseorang untuk tetap stagnan walaupun masa kerjanya terus bertambah. Tidak adanya suatu seminar maupun pelatihan mengenai suatu masalah kesehatan sebagai bentuk refreshing bagi petugas kesehatan dalam kurun waktu yang cukup lama dapat berakibat pada penampilan peran dan tanggung jawab yang cenderung relatif konstan dari waktu ke waktu. ${ }^{12}$

Selain itu, rendahnya akses layanan diagnosis cepat TCM serta kualitas layanan laboratorium yang masih terbatas sehingga untuk diagnosis khususnya TB-RO masih terbatas. Hal tersebut semakin diperparah dengan adanya desa-desa di Kalimantan Barat yang sulit untuk menjangkau fasilitas Kesehatan karena jarak yang jauh dan di pisahkan oleh sungai-sungai.

Waktu tempuh yang dirasa jauh ke pelayanan kesehatan juga menjadi alasan ketidak patuhan pasien TB. ${ }^{13}$ Tempat tinggal di pedesaan juga menjadi faktor yang mempengaruhi kepatuhan berobat berikutnya, pasien dari daerah pedesaan memiliki hasil pengobatan yang secara signifikan tidak berhasil dibandingkan dengan pasien dari 
daerah perkotaan. ${ }^{14}$ Faktor ini dapat diatasi dengan memberikan dukungan sosio-ekonomi kepada pasien misalnya dukungan pasien dengan memberi tunjangan transportasi untuk pasien dengan pendapatan rumah tangga rendah atau mereka yang harus melakukan perjalanan jauh ke pusat Kesehatan. ${ }^{15}$

\subsection{Belum optimalnya Active Case Finding}

Penemuan kasus kontak pasien TB secara aktif dapat berupa investigasi sekitar 10 hingga 15 orang kontak erat dengan pasien TB terutama untuk di tempat khusus seperti lapas/rutan, tempat kerja, asrama, pondok pesantren, sekolah, panti jompo dan pada populasi berisiko seperti tempat penampungan pengungsi dan daerah kumuh. ${ }^{16}$ Active case finding belum optimal disebabkan oleh beberapa faktor seperti belum optimalnya keterampilan petugas dalam melakukan skrining dua arah pada pasien HIV dengan $\mathrm{DM}^{17}$, pemberdayaan dan partisipasi masyarakat belum optimal, penemuan kasus aktif TB seperti investigasi kontak, penemuan pada populasi risiko tinggi dan rentan belum dilaksanakan secara optimal. ${ }^{18}$

1.3. Orang dengan gejala TB tidak mengakses layanan Kesehatan

Faktor lain yang menyebabkan rendahnya CDR TB adalah orang yang mengalami gejala TB tidak melaporkan dan mengakses fasilitas Kesehatan sehingga pasien tersebut tidak tercatat.

Faktor pertama yang menyebabkan penderita tidak mengakses layanan kesehatan adalah kurangnya pengetahuan tentang TB. Pengetahuan seseorang mempengaruhi perilaku individu. Semakin tinggi pengetahuan seseorang tentang kesehatan maka akan semakin tinggi kesehatan. Perilaku dapat terdiri dari pengetahuan dan tindakan, pengetahuan penderita TB paru yang kurang tentang cara penularan, bahaya dan cara pengobatan akan berpengaruh terhadap perilaku sebagai orang sakit dan akhirnya berakibat menjadi sumber penularan bagi orang disekelilingnya. ${ }^{19}$

Faktor kedua adalah akses layanan sulit dijangkau masyarakat. Wilayah geografis Kalimantan Barat yang terdiri dari banyak sungai di beberapa Kabupaten dan terdapat desa yang memiliki jarak yang jauh sehingga akses ke fasilitas pelayanan belum maksimal. Faktor jarak fasilitas kesehatan berhubungan dengan kepatuhan pengobatan TB paru. Penderita dengan jarak $>5 \mathrm{~km}$ lebih cenderung drop out dalam berobat, sehingga jarak tempat tinggal pasien TB dengan pelayanan kesehatan. ${ }^{20}$ Semakin jauh jarak dari rumah pasien dari tempat pelayanan kesehatan dan sulitnya transportasi maka, akan berhubungan dengan keteraturan berobat. Kurangnya sarana transportasi merupakan kendala dalam mencapai pelayanan kesehatan. ${ }^{20}$ Faktor jarak adalah suatu faktor penghambat untuk pemanfaatan pelayanan kesehatan. Tersedianya sarana transportasi akan memberi kemudahan dalam mendapatkan pelayanan kesehatan.

\subsection{Kasus TB yang tidak terlaporkan}

Selain adanya penemuan kasus secara aktif, penemuan kasus TB juga dapat dilakukan secara pasif dengan menunggu penderita maupun suspek TB memeriksakan dirinya ke fasilitas kesehatan. Masih banyak kasus TB yang didiagnosis di RS/Klinik Mandiri yang tidak dilaporkan ke Dinas Kesehatan. Hal ini disebabkan oleh jejaring internal dan external RS/Klinik Mandiri yang belum optimal. Belum semua suspek TB dari poli lain di RS di rujuk ke poli DOTS untuk dilakukan pemeriksaan dan penganmbilan register.

WHO memperkirakan bahwa hampir 40\% dari semua pasien dengan TB tidak dilaporkan/under-reporting ke program surveilans TB lokal atau nasional setiap tahun. ${ }^{21}$ Under-reporting case di terjemahkan sebagai proporsi jumlah kasus yang didiagnosis sebagai TB tetapi tidak dilaporkan ke sistem 
surveilans TB nasional yang dikelola oleh NTP (National TB Program) di semua layanan Kesehatan publik atau swasta di mana pasien TB didiagnosis meliputi apotek, dokter swasta, dokter anak, klinik swasta kecil, rumah sakit, dan laboratorium. ${ }^{22}$ Kasus TB yang tidak terlaporkan dapat menyebabkan masih adanya penularan di masyarakat.

2. Adanya penularan di masyarakat

Adanya penularan di masyarakat yang menyebabkan angka prevalensi TB masih tinggi. Terdapat beberapa hal yang menyebabkan masih tingginya penularan di masyarakat antara lain:

\subsection{Terjadinya peningkatan kepadatan penduduk}

Kepadatan penduduk di Kalimantan Barat pada tahun 2019 adalah sekitar 34,5 Jiwa per $\mathrm{km}^{2}$. Kota Pontianak merupakan ibu kota provinsi yang memiliki luas wilayah paling kecil diantara Kabupaten/Kota di Kalimantan Barat yaitu sekitar 107,80 km² dengan jumlah penduduk paling besar mencapai 646.661 jiwa atau sekitar $12,75 \%$ dari total penduduk Kalimantan Barat. Dengan demikian Kota Pontianak merupakan kota terpadat penduduknya yaitu 5.988 jiwa per $\mathrm{km}^{2}$. Hal berbanding lurus dengan tingginya kasus TB di Kota Pontianak. Kasus TB di Kota Pontianak pada tahun 2019 menempati urutan pertama dengan jumlah kasus terbanyak (1.511 kasus) jika dibandingkan $13 \mathrm{Kab} /$ Kota lainnya di Kalimantan Barat. $^{4}$ Di kota-kota dengan kepadatan penduduk $>80$ orang $/ \mathrm{km}^{2}$, kejadian TB 4,18 kali lipat lebih tinggi daripada di kotakota dengan tingkat kepadatan penduduk yang lebih rendah. ${ }^{23}$

Kepadatan perumahan yang lebih tinggi dikaitkan dengan risiko tuberkulosis yang lebih besar, sementara kepadatan penduduk yang berlebihan meningkatkan kemungkinan terinfeksi secara signifikan. ${ }^{24}$ Kepadatan penduduk dan kurangnya perencanaan kota dapat memperburuk kerentanan sosial yang ada seperti kurangnya sanitasi, perumahan yang tidak memadai, transportasi umum yang padat dan kelebihan layanan kesehatan. Kepadatan penduduk memainkan peran penting dalam penentuan spasial tuberkulosis bahkan setelah penyesuaian untuk pendapatan. ${ }^{25}$

Identifikasi kecamatan dengan prevalensi TB tinggi dan kepadatan penduduk tinggi dapat digunakan untuk mendukung program pengendalian tuberkulosis, khususnya untuk menjangkau populasi yang berisiko, penguatan manajemen TB dan mengintensifkan penemuan kasus. ${ }^{26}$

\subsection{Pasien TB tidak menyelesaikan pengobatan}

Terdapat beberapa faktor yang menenyebabkan pasien TB tidak menyelesaikan pengobatannya hingga tuntas dan sembuh. Pengetahuan merupakan salah satu faktor risiko kepatuhan minum obat. ${ }^{27}$ Pada penelitian di Shenzen, Cina menunjukan bahwa diantara pasien TB, kurangnya pengetahuan tentang pengobatan TB dan waktu perjalanan yang lebih lama ke Puskesmas terdekat adalah faktor paling signifikan yang memprediksi ketidakpatuhan. $^{28}$ Penelitian di Anhui, mengungkapkan bahwa kurangnya pengetahuan pasien TB paru disebabkan oleh tingkat pendidikan yang rendah, karena semakin rendah tingkat pendidikannya, semakin rendah juga tingkat penyelesaian pengobatnya. $^{29}$ Di Jayapura, Indonesia penyebab ketidakpatuhan pasien TB paru meminum obat adalah pengetahuan yang rendah tentang penyebab $\mathrm{TB}$, penularan TB, dan pengaruh pengobatan TB yang tidak selesai, menurut peneliti promosi kesehatan yang intensif kepada masyarakat dan pendidikan rutin pasien oleh staf perawatan kesehatan dapat mengatasi masalah ini. ${ }^{15}$ Cara peningkatan kepatuhan dapat dilakukan dengan modifikasi lingkungan, pendidikan, sosial, akomodasi, peningkatan interaksi antara 
petugas kesehatan dengan pasien serta perubahan model terapi. ${ }^{30}$

Kemudian faktor lain penyebab pasien TB tidak menyelesaikan pengobatan adalah belum optimalnya dukungan anggota keluarga terkait pengobatan pasien TB hingga tuntas. Anggota keluarga yang memiliki pengetahuan tentang pengobatan TB paru dan tidak sibuk dengan pekerjaanya dapat meningkatkan signifikansi anggota keluarganya yang mengidap TB paru untuk patuh dalam meminum obat, selain itu dukungan anggota keluarga memainkan peran penting dalam ketaatan pengobatan karena dapat memberikan pengertian agar anggota keluarga yang mengidap TB paru tetap melanjutkan pengobatanya. ${ }^{31}$ Dukungan keluarga merupakan komponen penting dalam keberhasilan pengobatan pasien TB paru. Dengan dukungan kesehatan yang diberikan oleh keluarga kepada pasien TB Paru dapat meningkatkan motivasi untuk patuh dalam melakukan pengobatan rutin TB paru. ${ }^{32}$

Pekerjaan merupakan faktor selanjutnya yang mempengaruhi kepatuhan minum obat pada pasien TB paru. Faktor pekerjaan sangat mendukung kepatuhan berobat oleh karena itu, pemerintah harus mempertimbangkan status pekerjaan pasien ketika mereka merumuskan kebijakan yang mendukung untuk mempromosikan kepatuhan pengobatan antiTB. ${ }^{27}$ Perilaku dan sikap pasien yang telah muncul gejala membaik dan lupa meminum obat karena kesibukan pekerjaan menyebabkan pasien TB paru menghentikan pengobatanya. ${ }^{33}$

Pada penderita yang tidak memiliki pendapatan tetap menunjukan kepatuhan minum obat yang tidak memadai karena penyakit TB ini dapat menyebabkan beban keuangan yang berat pada keluarga pasien yang tidak memiliki pendapatan. ${ }^{27}$ Hasil penelitian penderita TB paru di Myanmar mayoritas responden menyatakan kekhawatiran finansial sebagai faktor utama hambatan yang dirasakan terhadap kepatuhan berobat. Mereka tidak mampu mengunjungi pusat pelayanan kesehatan karena biaya perjalanan yang mahal dan membeli obat tonik dan obat untuk komorbid. ${ }^{34}$

Biaya pengobatan anti-TB tetap menjadi tantangan serius dalam menurunkan angka ketidakpatuhan berobat. Pasien TB paru mengkhawatirkan biaya pengobatan, akomodasi dan transportasi. Obat-obatan yang dibutuhkan seperti yang berkaitan dengan gejala pernapasan, perlindungan hati, atau efek samping. Lalu disebutkan bahwa desentralisasi pengambilan obat dapat mengurangi beban dan dirasa lebih efisien bagi penderita TB paru. Program pembiayaan perawatan kesehatan juga harus mempertimbangkan pasien TB untuk membebaskan biaya yang terkait dengan reaksi merugikan dari obat anti-TB. ${ }^{35}$

3. Kasus TB anak

Hasil penelitian Hajarsyah dkk menyatakan bahwa, faktor risiko yang paling berpengaruh terhadap kejadian TB pada anakanak adalah status gizi, lalu diikuti status imunisasi, jumlah orang yang tinggal dalam satu rumah, dan kebiasaan tidur dalam satu ranjang. ${ }^{36}$

Sumber penularan utama TB anak adalah penderita TB dewasa terutama yang kontak erat seperti orangtua, orang serumah ataupun orang yang sering berinteraksi langsung. ${ }^{37}$ Hasil penelitian terdahulu mendapatkan bahwa kelompok anak yang menderita TB paru memiliki risiko 6,378 kali lebih besar dibandingkan kelompok anak yang tidak menderita TB berdasarkan adanya riwayat kontak TB. ${ }^{38}$ Cakupan imunisasi dasar lengkap di Kalimantan Barat pada tahun 2015-2019 masih berada dibawah standar IDL nasional yaitu sebesar $90 \%$. Hal dapat menjadi faktor risiko penyebab terjadinya kasus TB anak. Anak yang tidak mendapatkan imunisasi BCG mempunyai risiko 2,59 kali lebih besar untuk terkena TB paru dibandingkan dengan anak yang mendapatkan imunisasi BCG. ${ }^{39}$ Kejadian 
kasus TB anak tinggi pada usia $0-1$ tahun dan 12-14 tahun. Kejadian tinggi pada anak usia 01 tahun dapat dikaitkan dengan imunitas dan kontak erat dengan pasien TB dalam keluarga. ${ }^{39} 40$ Sedangkan TB anak pada usia 1214 tahun terkait dengan durasi perlindungan BCG selama 10 tahun. $^{41}$ Imunisasi BCG termasuk dalam program imunisasi rutin untuk mencegah terjadinya TB yang parah. Imunisasi ini diberikan satu kali untuk anak di bawah 3 tahun. ${ }^{37}$

\section{Beberapa Alternatif Solusi}

1. Mengembangkan sistem rujukan terduga TB yang datang ke layanan kesehatan berbasis masyarakat

Untuk meningkatkan jumlah orang dengan gejala TB atau dengan TB yang mengakses pelayanan kesehatan, maka perlu adanya intervensi untuk mendorong mereka yang sudah datang ke layanan L0 untuk dapat didiagnosis dan dilaporkan dengan membuat jejaring rujukan layanan dari L0 ke fasilitas pelayanan kesehatan TB yang sudah ada. Pembentukan jejaring layanan perlu melibatkan asosiasi profesi farmasi (IAI, PAFI) ke dalam KOPI TB di daerah. ${ }^{17}$

2. Peningkatan surveilens rutin yang disertai supervisi yang berkualitas di tingkat fasilitas pelayanan kesehatan

Sistem surveilens SITB yang baru didorong menjadi sistem surveilens yang dapat melakukan monitoring dan manajemen kinerja program yang real time. ${ }^{42}$ Selain itu akan dikembangkan integrasi antara sistem informasi TB dengan sistem informasi kesehatan milik fasyankes (SIRS) dan BPJS (P-Care, V Claim) untuk mendapatkan data secara sistematis dan konsisten tanpa melakukan kegiatan mopping up yang bersifat masif dan mahal. ${ }^{43}$
3. Implementasi penggunaan obat baru dan paduan standar jangka pendek untuk meningkatkan kualitas pengobatan pasien TB-RO di Indonesia

Perlu adanya regulasi penggunaan paduan obat baru sesuai dengan rekomendasi WHO. Ketersediaan obat baru perlu didorong melalui proses registrasi yang cepat agar dapat diproduksi dan diadakan di dalam negeri untuk menjamin akses pasien TB terhadap pengobatan TB yang terbaik dan bermutu. Penggunaan paduan obat baru tanpa suntikan berjangka pendek juga membuka peluang untuk melakukan desentralisasi layanan TB-RO ke fasilitas layanan primer untuk menginisiasi pengobatan dan penerapan pemantuan pengobatan di tingkat komunitas sehingga akan mengurangi beban dan tantangan bagi pasien TB-RO untuk bisa menyelesaikan pengobatan. $^{44} 45$

4. Skrining dan penemuan kasus pada populasi risiko tinggi

Upaya skrining dan penemuan kasus secara aktif di masyarakat dapat melibatkan pegiat TB atau kader. Pelibatan kader terbukti efektif untuk meningkatkan jumlah kasus TB secara signifikan. ${ }^{46}$ Intervensi tersebut ke depan harus diimplementasikan di setiap Puskemas. Upaya penemuan kasus TB anak perlu melibatkan dokter praktik mandiri. ${ }^{17} 47$

5. Melakukan kajian multisektoral untuk melakukan monitoring dan evaluasi pencapaian dan tantangan penanggulangan TB di Indonesia

Kajian multisektoral melibatkan seluruh pemangku kepentingan di tingkat nasional, provinsi dan Kab/Kota. Kajian menggunakan pendekatan PCF menggunakan datadata epidemiologi, sistem kesehatan dan lain yang dapat menggambarkan pencapaian dan akar masalahnya. Selanjutnya dilakukan diskusi untuk merumuskan strategi-strategi 
implementasi upaya penanggulangan 20202024 yang sesuai. ${ }^{17}$

6. Memperkuat dukungan pembiayaan melalui Jaminan Kesehatan Nasional untuk penemuan kasus TB.

Perlu dilakukan pertemuan-pertemuan koordinasi dengan BPJS agar penyesuaian alur diagnosis TB dengan penambahan prosedur skrining dengan ronsen dada, skrining bi-directional bagi penyakit komorbid dan pemberian terapi pencegahan TB dapat dibiayai melalui skema JKN. Selain itu, layanan apotek perlu dimasukkan dalam layanan Program Rujuk Balik sehingga layanan apotek dapat melakukan MTM (Medication Therapy Management). ${ }^{17} 48$

\section{Kesimpulan}

Prioritas utama masalah penyakit menular di Kalimantan Barat berdasarkan hasil skoring menggunkan metode PAHO adopted Hanlon adalah TB dengan total skor sebesar 25,16 . Kedua adalah DBD dengan total skor sebesar 24,08 dan ketiga adalah HIV/AIDS dengan total skor sebesar 23,80. TB menjadi prioritas masalah pertama dalam penelitian ini karena penemuan kasus yang belum optimal, adanya penularan di masyarakat dan masih adanya kasus TB anak.

Beberapa usulan yang bisa penulisan berikan dalam menaggulangi permasalahan TB antara lain skrining dan penemuan kasus pada populasi risiko tinggi; peningkatan surveilens rutin yang disertai supervisi yang berkualitas di tingkat fasilitas pelayanan kesehatan serta implementasi penggunaan obat baru dan paduan standar jangka pendek untuk meningkatkan kualitas pengobatan pasien TB RO di Indonesia.

\section{Ucapan Terima Kasih}

Terima kasih kepada seluruh ketua, staff dan jajaran bidang Surveilans dan Imunisasi
Pencegahan dan Pengendalian Penyakit Dinas Kesehatan Provinsi Kalimantan Barat yang telah berkenan menerima, membimbing dan memberikan data yang dibutuhkan dalam proses penyusunan penelitian Analisis Situasi Masalah Kesehatan di Kalimantan Barat. Serta terimakasih kepada teman-teman FETP UI yang telah bahu-membahu saling membantu dalam dalam proses penyusunan penelitian ini.

\section{Daftar Pustaka}

1. Cahyani DI, Kartasurya MI, Rahfiludin MZ. 2020. Gerakan masyarakat hidup sehat dalam perspektif implementasi kebijakan (studi kualitatif). Jurnal Kesehatan Masyarakat Indonesia. 215(1):10. Available from: https://doi.org 10.26714 /jkmi.15. 1.2020.10-18.

2. Kemenkes RI. 2018. Riskesdas Nasional 2018. pdf. Badan Penelitian dan Pengembangan Kesehatan. Published online 201.8.627. Available from: https://doi.org ISBN 978-02-373-118-3.

3. Dirjen P2P Kemkes RI. 2020. Rencana Aksi Program 2020-2024. Jurnal Ilmu Teknosains. 2 (1/Mei):1-33. Available from:https://e-renggar.kemkes.go.id/file 2018/e-performance/1-465827-3tahun an- 684.

4. Dinas Kesehatan Provinsi Kalimantan Barat. 2019. Profil Kesehatan Provinsi Kalimantan Barat Tahun 2019. (Pusat Data dan Informasi Dinkes Provinsi Kalimantan Barat, ed.). Available from: https://drive.google.com/drive/folders/1 XYHFQuKucZIwmCADX5ff1DhfJgqz I-1.

5. Dinas Kesehatan Provinsi Kalimantan Barat. 2017. Profil Kesehatan Provinsi Kalimantan Barat Tahun 2017. (Barat PD dan IDPK, ed.). SIK. 
6. Dinas Kesehatan Provinsi Kalimantan Barat. 2016. Profil Kesehatan Provinsi Kalimantan Barat Tahun 2016. (Barat PD dan IDPK, ed.). SIK. Available from: https://drive.google.com/drive/ folders/1XYHFQuKucZIwmCADX5ff1 aDhfJgqzI-1.

7. Dinas Kesehatan Provinsi Kalimantan Barat. 2015. Profil Kesehatan Provinsi Kalimantan Barat Tahun 2015. (Barat PD dan IDPK, ed.). SIK. Available from: https://drive.google.com/drive/ folders/1XYHFQuKucZIwmCADX5ff1 aDhfJgqzI-1.

8. Dinas Kesehatan Provinsi Kalimantan Barat. 2018. Profil Kesehatan Provinsi Kalimantan Barat Tahun 2018. (Pusat Data dan Informasi Dinkes Provinsi Kalimantan Barat, ed.). SIK.

9. Kemenkes RI. 2018. Tuberkulosis (TB). Tuberkulosis.1 April 2018. Available from: www.kemenkes.go.id.

10. Surya A, Setyaningsih B, Suryani N.H, et al. 2017. Quality tuberculosis care in indonesia: using patient pathway analysis to optimize public - private collaboration. J Infect Dis.216 (Suppl7): S724-S732. Available from: https://doi.org 10.1093/infdis/jix379.

11. Kemenkes RI. 2019. Panduan penerapan jejaring layanan tuberkulosis di fasilitas kesehatan pemerintah dan swasta berbasis kabupaten/kota (Distric-Based Public-Private Mix/ DPPM). Published online: $1-50$.

12. Buiatria L. 2011. No Title p. Phys Rev E. Published online 2011. Available from: http://www.ainfo.inia.uy/digital /bitstream/item/7130/1/LUZARDOBUI ATRIA2017.
13. Tesfahuneygn G, Medhin G, Legesse M. 2015. Adherence to Anti-tuberculosis treatment and treatment outcomes among tuberculosis patients in Alamata District, northeast Ethiopia. BMC Res Notes. 8:503. Available from: https://doi.org10.1186/s13104-015-14 52-x.

14. Ejeta E, Beyene G, Balay G, Bonsa Z, Abebe G. 2018. Factors associated with unsuccessful treatment outcome in tuberculosis patients among refugees and their surrounding communities in Gambella Regional State, Ethiopia. PLoS One.13(10):e0205468-e0205468. Available from: https://doi.org 10.1371 /journal.pone.0205468.

15. Ruru Y, Matasik M, Oktavian A, et al. 2018. Factors associated with nonadherence during tuberculosis treatment among patients treated with DOTS strategy in Jayapura, Papua Province, Indonesia. Glob Health Action. 11(1):1510592. Available from: https://doi.org10.1080/16549716.2018. 1510592.

16. Kemenkes RI. 2016. Peraturan Menteri Kesehatan RI Nomor 67 Tahun 2016 Tentang Penanggulangan Tuberkulosis.

17. Kemenkes RI. 2020. Strategi nasional penanggulangan tuberkulosis di Indonesia 2020-2024. Pertemuan Konsolidasi Nasional Penyusunan STRANAS TB:135.

18. WHO. 2009. Global Tuberculosis Control. Tuberculosis. Published online: 17 . 
19. Kurniasih ND, Widianingsih C. 2013. Pencegahan Penularan $\mathrm{Tb}$ Pada Penderita Tb Paru Di Poli Paru Rumah Sakit Prof. Dr. Sulianti Saroso. Indonesia J Infect Dis.28-31. Available from:http://ijidrspisuliantisaroso.co.id/i ndex.php/ijid/article/view/10.

20. Ulfah U, Windiyaningsih C, Abidin Z, Murtiani F. 2018. Faktor - Faktor yang berhubungan dengan kepatuhan berobat pada penderita tuberkulosis paru. Indonesia Jurnal Infect Dis. 2018;4(1). Available from: https://doi.org 10.32667/ijid.v4i1.44.

21. Tollefson D, Ngari F, Mwakala M, et al. Under-reporting of sputum smearpositive tuberculosis cases in Kenya. Int J Tuberc Lung Dis. 2016;20(10):13341341. Available from: https://doi.org 10.5588/ijtld.16.0156.

22. Rusnoto, Murti B, Reviono, Widyaningsih V, Pamungkasari CUW. 2021. Indeks prediktif under-reporting case TBC rumah sakit. 2021:1116-1123.

23. Tanrikulu AC, Acemoglu H, Palanci Y, Eren Dagli C. 2008. Tuberculosis in Turkey: high altitude and other socioeconomi risk factors. Public Health.122(6):613-619. Available from: https://doi.org/10.1016/j.puhe.2007.09. 005.

24. Clark M, Riben P, Nowgesic E. 2002. The association of housing density, isolation and tuberculosis in Canadian First Nations communities. Int $\mathbf{J}$ Epidemiol. 31(5):940-945. Available from: https://doi.org 10.1093/ije/31.5. 940.
25. de Abreu e Silva M, Di Lorenzo Oliveira C, Teixeira Neto RG, Camargos PA. 2016. Spatial distribution of tuberculosis from 2002 to 2012 in a midsize city in Brazil. BMC Public Health. 16(1):912. Available from: https://doi.org 10.1186/ s12889-016-3575-y.

26. Rohman H. 2017. Pola Spasial persebaran kasus tuberkulosis paru terhadap kepadatan penduduk. Jurnal Kesehatan Masyarakat. (978-602-636347-3):8-16.

27. Du L, Chen X, Zhu X, et al. 2020. Determinants of medication adherence for pulmonary tuberculosis patients during continuation phase in Dalian, Northeast China. Patient Prefer Adherence. 14:1119-1128. Available from: https://doi.org 10.2147/ PPA.S243734.

28. Tang Y, Zhao M, Wang Y, et al. 2015. Non-adherence to anti-tuberculosis treatment among internal migrants with pulmonary tuberculosis in Shenzhen, China: a cross-sectional study. BMC Public Health. 15:474. Available from: https://doi.org 10.1186/s12889-0151789-z.

29. Fang X-H, Shen $\mathrm{H}-\mathrm{H}, \mathrm{Hu} \mathrm{W}-\mathrm{Q}$, et al. 2019. Prevalence of and Factors influencing anti-tuberculosis treatment non-adherence among patients with pulmonary tuberculosis: a crosssectional study in Anhui Province, Eastern China. Med Sci Monit. 25: 1928-1935. Available from: https://doi.org 10.12659/MSM.913510.

30. Sukartini T. 2015. Pengembangan Model Peningkatan Kepatuhan. Disertasi. (April). 
31. Zhang J, Yang Y, Qiao X, et al. 2020. Factors influencing medication nonadherence to pulmonary tuberculosis treatment in tibet, china: a qualitative study from the patient perspective. patient prefer adherence.14:1149-1158. Available from:https://doi.org/10.2147/ PPA.S252448.

32. Arfamaini R. 2016. Factors affecting medication adherence among vietnamese immigrants. Appl Microbiol Biotechnol. 85(1): 2071-2079.

33. Fang XH, Shen HH, Hu WQ, et al. 2019. Prevalence of and factors influencing anti-tuberculosis treatment nonadherence among patients with pulmonary tuberculosis: A crosssectional study in Anhui Province, Eastern China. Med Sci Monit.25:19281935. Available from: https://doi.org10.12659/MSM.91 3510.

34. Onainor ER. 2019. Factors associated with tuberculosis treatment default amongst migrant and mobile populations in Myanmar. 1:105-112.

35. Woimo TT, Yimer WK, Bati T, Gesesew HA. 2017. The prevalence and factors associated for anti-tuberculosis treatment non-adherence among pulmonary tuberculosis patients in public health care facilities in South Ethiopia: a cross-sectional study. BMC Public Health. 17(1):269. Available from:https://doi.org/10.1186/ s12889017-4188-9.

36. Pratama YA. 2021. Karakteristik klinis penyakit tuberkulosis paru pada anak. J Penelit Perawat Prof. 3(2):237-242. Available from: https://doi.org/10. 37287/ jppp.v3i2.403.
37. Suryaningtyas NH, Inzana N. 2020. Gambaran kejadian Tb anak berdasarkan cakupan imunisasi BCG dan lingkungan rumah di Provinsi Jawa Tengah Tahun 2017 Dan 2018. Sel J Penelitian Kesehatan. 2020;7(1):19-32. Available from: https://doi.org/10. 22435/sel.v7i1. 3453.

38. Yulistyaningrum, Sri Rejeki DS. 2014. Hubungan riwayat kontak penderita tuberkulosis paru $(\mathrm{Tb})$ dengan kejadian $\mathrm{Tb}$ paru anak di balai pengobatan penyakit paru-paru (Bp4) Purwokerto. Jurnal Kesehatan Masyarakat (Journal Public Health. 4(1):43-48. Available from:https://doi.org/10.12928/kesmas.v 4i1.1101.

39. Apriadisiregar PA, Gurning FP, Eliska E, Pratama MY. 2018. Analysis of factors associated with pulmonary tuberculosis incidence of children in Sibuhuan General Hospital. Jurnal Berk Epidemiologi. 6(3):268. Available from: https://doi.org/10.20473/jbe. v6i32018.268-275.

40. Boisson-Dupuis S, Bustamante J, ElBaghdadi J, et al. 2015. Inherited and acquired immunodeficiencies underlying tuberculosis in childhood. Immunol Rev.264(1):103-120. Available from: https://doi.org/10.1111/imr. 12272.

41. Eisenhut M, Paranjothy S, Abubakar I, et al. 2009. BCG vaccination reduces risk of infection with Mycobacterium tuberculosis as detected by gamma interferon release assay. Vaccine. 27(44):6116-6120. Available from: https://doi.org/10.1016/j.vaccine. 2009.08.031. 
42. Kesehatan K. Petunjuk teknis integrasi data TB. Published online 2018.

43. Kementrian Kesehatan Republik Indonesia. The Republic of Indonesia joint external monitoring mission for Tuberculosis. Published online 2020.

44. Purnama SG. Buku Petunjuk Teknis Manajemen dan tatalaksana TB Anak. Minist Heal Republik Indonesia. Published online 2016:112.
45. Mollona E, Aivazidou E, Barberio V, Cunico G, Pareschi L. 2019. Guidelines on Cohesion Policy Commun. 14. Available

from:https://doi.org/10.6092/unibo/ams acta/6247.

46. Khoirul HU. 2018. Model Skrining Massal Tuberkulosis Kasus Dan Kasus Tuberkulosis (TBC) Paru Di Lembaga Permasyarakatan Kelas II A Kabupaten Jember.

47. Wibisana W. 2019. Penguatan Sistem Pelayanan Kesehatan. 